\title{
Drug Lag for Inflammatory Bowel Disease Treatments in the East and West
}

\author{
Shinji Okabayashi Taku Kobayashi Toshifumi Hibi \\ Center for Advanced IBD Research and Treatment, Kitasato University Kitasato Institute Hospital, Tokyo, Japan
}

\section{Keywords}

Approval lag · Crohn's disease - Drug lag · Inflammatory bowel disease $\cdot$ Drug approval $\cdot$ Ulcerative colitis

\begin{abstract}
Background: Inflammatory bowel disease (IBD), though historically common in the West, is now increasingly prevalent in industrializing countries. A simultaneous dramatic increase in IBD drug options has enabled most patients to achieve remission. Nevertheless, worldwide disparities in the approval of IBD drugs, or "drug lag", remain problematic. Summary: Drug lag for major IBD drugs before March 31, 2018 ( 12 for Crohn's disease [CD] and 13 for ulcerative colitis [UC]) was compared between that of the United States (US), European Union (EU), and Asia (Japan, China, South Korea, Taiwan, and the Philippines) to assess current trends. In the US, unapproved IBD drugs accounted for $16.7 \%(2 / 12)$ for CD and $23.1 \%$ (3/13) for UC; approval lag was 3.8 (0-80.5) months for $C D$ and 3.6 (0-88) months for UC. In the EU, unapproved drugs accounted for $16.7 \%(2 / 12)$ for $C D$ and $15.4 \%(2 / 13)$ for UC; approval lag was $0.03(0-13.9)$ months for CD and 0 (013.9) months for UC. This demonstrates the short drug lag in both regions, although one drug developed in a joint US/EU
\end{abstract}

\section{KARGER}

(c) 2018 S. Karger AG, Basel

E-Mail karger@karger.com

www.karger.com/iid clinical trial had around a 350-day approval lag. In Asia, the proportion of unapproved IBD drugs was the lowest in Japan at $33.3 \%(4 / 12)$ for CD and $23.1 \%$ (3/13) for UC; South Korea had the shortest lag for CD at 13.2 (0-133.1) months and the Philippines had the shortest lag for UC at 9.9 (0.6-176.2) months, but these countries still had longer lag periods than the West. However, a proportion of unapproved drugs and approval lag has decreased considerably in Asia since the start of the biologics era. Key Messages: Despite the recent shortening drug lag between different countries and regions, this study shows that disparities persist. With globalization, eliminating these disparate drug lags is necessary to manage IBD and may require efforts toward international adoption of a more standardized approval process.

(c) 2018 S. Karger AG, Basel

\section{Introduction}

Inflammatory bowel disease (IBD), a general term for ulcerative colitis (UC) and Crohn's disease (CD), is an idiopathic disease characterized by repeated chronic inflammation confined to the gastrointestinal tract [1]. IBD has long been common in Western countries, but it has 
been increasing in its prevalence mainly in newly industrializing countries since the start of the 21 st century [2, $3]$ and particularly rapidly in Japan and other Asian countries [3-5]. IBD is becoming a major social problem because adults of working age often need to spend time taking care of themselves because of the disease $[6,7]$ and treatment is expensive [8-10].

The cause of IBD is still unknown, so there is no known cure and the current goal of treatment is maintenance of remission [11-13]. For many years, IBD was treated with 5-aminosalicylic acid (5-ASA) drugs, steroids (prednisone), and thiopurine immunomodulators (azathioprine and 6-mercaptopurine). Surgery was often performed when these drugs were not effective. Treatment of such refractory cases remained a challenge for some time, but gradual improvement in understanding the pathology of IBD and recent developments in drug discovery technology has resulted in a marked increase in the number of drugs available for refractory IBD. Among them, calcineurin inhibitors (cyclosporine and tacrolimus) $[14,15]$ and biologics [16-24] have been highly effective in refractory cases, and the advent of the biologic anti-tumor necrosis factor alpha antibody in particular has revolutionized the treatment of IBD [25]. Drugs with other targets such as non-tumor necrosis factor alpha cytokines and adhesion molecules have also been developed [26-29], and several clinical trials are underway [30]. Despite the increased number of IBD drugs available, there are still disparities between those approved and available in different areas globally, a phenomenon referred to as "drug lag". Some previous studies have compared approval lag for various drugs between a large number of countries [31-38], but none have examined approval lag for IBD drugs. Therefore, we decided to examine approval lag for major IBD drugs in the United States (US), the European Union (EU), and Asia in this study.

\section{Methods}

\section{Countries and IBD Drugs Evaluated}

Data as of March 31, 2018 from the US, EU, and Asia (Japan, China, South Korea, Taiwan, and the Philippines) were analyzed. China was ultimately excluded due to the difficulty encountered in collecting accurate data.

We evaluated major IBD drugs with at least one of the following products approved in any of the countries evaluated: oral 5-ASA drugs (salazosulfapyridine, Pentasa ${ }^{\circledR}$, Asacol ${ }^{\circledR}$ and Lial$\mathrm{da}^{\circledR}$ ), steroids (prednisone and oral budesonide), cytapheresis, immunomodulators (azathioprine, 6-mercaptopurine, tacrolimus, and cyclosporine), and biologics (infliximab, infliximab biosimilar [CT-P13], adalimumab, certolizumab, golimumab, vedolizumab,
Table 1. Absolute drug lag in CD and UC

\begin{tabular}{lclll}
\hline & All drugs & 5-ASA & IM & Biologics \\
\hline CD & & & & \\
USA & $2 / 12(16.7)$ & $0 / 2(0)$ & $2 / 2(100)$ & $0 / 7(0)$ \\
EU & $2 / 12(16.7)$ & $0 / 2(0)$ & $1 / 2(50)$ & $1 / 7(14.3)$ \\
JPN & $4 / 12(33.3)$ & $0 / 2(0)$ & $1 / 2(50)$ & $3 / 7(42.9)$ \\
KOR & $5 / 12(41.7)$ & $1 / 2(50)$ & $0 / 2(0)$ & $3 / 7(42.9)$ \\
TWN & $8 / 12(66.7)$ & $2 / 2(100)$ & $2 / 2(100)$ & $3 / 7(42.9)$ \\
PHL & $7 / 12(58.3)$ & $1 / 2(50)$ & $2 / 2(100)$ & $3 / 7(42.9)$ \\
UC & & & & \\
USA & $3 / 13(23.1)$ & $0 / 4(0)$ & $3 / 3(100)$ & $0 / 5(0)$ \\
EU & $2 / 13(15.4)$ & $0 / 4(0)$ & $2 / 3(66.7)$ & $0 / 5(0)$ \\
JPN & $3 / 13(23.1)$ & $0 / 4(0)$ & $1 / 3(33.3)$ & $1 / 5(20)$ \\
KOR & $3 / 13(23.1)$ & $1 / 4(25)$ & $1 / 3(33.3)$ & $0 / 5(0)$ \\
TWN & $6 / 13(46.2)$ & $2 / 4(50)$ & $3 / 3(100)$ & $0 / 5(0)$ \\
PHL & $10 / 13(76.9)$ & $3 / 4(75)$ & $3 / 3(100)$ & $3 / 5(60)$ \\
\hline
\end{tabular}

Proportion of unapproved drugs in each country, $n(\%)$.

5-ASA, 5-aminosalicylic acid drugs; CD, Crohn's disease; UC, ulcerative colitis; EU, European Union; IM, immunomodulators; JPN, Japan; KOR, Republic of Korea; PHL, Republic of the Philippines; TWN, Taiwan; USA, United States of America.

natalizumab, and ustekinumab). We excluded prednisone because of the difficulty faced determining approval dates, excluded cyclosporine because it has not been officially approved in any of the evaluated countries, and excluded cytapheresis because it has been approved only in Japan. Ultimately, 12 CD drugs and 13 UC drugs were evaluated. "Biologics-era" drugs are defined as the first biologic for IBD approved in 1998 and all subsequently approved drugs among the evaluated drugs (Lialda ${ }^{\circledR}$, oral budesonide [for UC], tacrolimus, 6-mercaptopurine, and all biologics).

Determination of IBD Drug Approval Dates in Each Region

Approval dates for evaluated drugs were confirmed by contacting their respective manufacturers. If certain information was difficult to obtain in Asia, it was obtained by directly contacting physicians at specialist IBD hospitals in each country. The drug approval date was defined as the date of regulatory approval by the regional regulatory authority and not as the date of insurance approval or marketing. The dates of regulatory approval were identified as the dates of approval decisions by the US Food and Drug Administration (FDA), the European Medicines Agency (EMA), the Pharmaceuticals and Medical Devices Agency (PMDA) in Japan, the Ministry of Food and Drug Safety (MFDS) in South Korea, the Taiwan Food and Drug Administration (TFDA) in Taiwan, and the Food and Drug Administration Philippines (FDAP).

\section{Comparison of IBD Drug Lag between Regions}

The concept of drug lag consists of "absolute drug lag" and "relative drug lag" [34]. Absolute drug lag is an index of the percentage of unapproved drugs in each region and relative drug lag is an index of the delay in approval in a certain region after the drug's first approval. In this study, we examined relative drug lag along with (1) the proportion of first approvals in each region and 
Table 2. Relative drug lag in CD and UC

\begin{tabular}{llllcc}
\hline & \multicolumn{2}{l}{ First approval, $n(\%)$} & & \multicolumn{2}{l}{ Approval lag, months (range) } \\
\cline { 5 - 6 } & all drugs & biologics & & all drugs & biologics \\
\hline CD & & & & & \\
USA & $5 / 12(41.7)$ & $5 / 7(71.4)$ & & $3.8(0-80.5)$ & $0(0-45.2)$ \\
EU & $5 / 12(41.7)$ & $1 / 7(14.3)$ & & $0.03(0-13.9)$ & $2.4(0-13.9)$ \\
JPN & $0 / 12(0)$ & $0 / 7(0)$ & & $74.2(6.2-687.4)$ & $32.6(6.2-44.7)$ \\
KOR & $2 / 12(16.7)$ & $1 / 7(14.3)$ & & $13.2(0-133.1)$ & $11.0(0-14.4)$ \\
TWN & $0 / 12(0)$ & $0 / 7(0)$ & & $42.1(10.1-207.2)$ & $42.1(10.1-207.2)$ \\
PHL & $0 / 12(0)$ & $0 / 7(0)$ & & $33.7(9.9-176.2)$ & $25.6(9.9-109)$ \\
UC & & & & & \\
USA & $4 / 13(30.7)$ & $3 / 5(60)$ & & $3.6(0-88)$ & $0(0-45.2)$ \\
EU & $6 / 13(46.2)$ & $1 / 5(20)$ & & $0(0-13.9)$ & $4.2(0-13.9)$ \\
JPN & $1 / 13(7.7)$ & $0 / 5(0)$ & & $80.9(0-687.4)$ & $35.5(14.3-57.9)$ \\
KOR & $2 / 13(15.4)$ & $1 / 5(20)$ & & $16.5(0-133.1)$ & $12.4(0-19.8)$ \\
TWN & $0 / 13(0)$ & $0 / 5(0)$ & & $53.9(10.1-147.8)$ & $30.4(10.1-121.3)$ \\
PHL & $0 / 13(0)$ & $0 / 5(0)$ & & $9.9(0.6-176.2)$ & $5.3(0.6-9.9)$ \\
\hline
\end{tabular}

Proportion of first approval and approval lag in each country. CD, Crohn's disease; UC, ulcerative colitis; EU, European Union; JPN, Japan; KOR, Republic of Korea; PHL, Republic of the Philippines; TWN, Taiwan; USA, United States of America.

(2) the time from the drug's first approval to approval in other regions (i.e., approval lag). Absolute drug lag and relative drug lag were also calculated separately for UC and CD in a cross-sectional analytical design.

\section{Statistical Analysis}

All numerical values are shown as the median (range). Differences between 2 groups were analyzed using the Mann-Whitney $\mathrm{U}$ test, and a $p$ value of $\leq 0.05$ was considered statistically significant. Statistical analysis was performed using GraphPad Prism ${ }^{\mathrm{TM}}$ software, version 6.0 (GraphPad Software, Inc., La Jolla, CA, USA).

\section{Results}

The dates of regulatory approval of the evaluated IBD drugs (12 for CD and 13 for UC) for each region are shown in the online supplementary Table (see www. karger.com/doi/10.1159/000491878 for all online suppl. material).

\section{Drug Lag in the US}

Unapproved IBD drugs accounted for $16.7 \%(2 / 12)$ for CD and 23.1\% (3/13) for UC. Absolute drug lag for $\mathrm{CD}$ was the smallest among regions (tied with the EU), and absolute drug lag for UC was the second smallest after the EU (Table 1). All biologics-era drugs for both CD and UC were approved, so there was no absolute drug lag. Relative drug lag was also short in the US at $3.8(0-$
80.5) months overall for $\mathrm{CD}$ and 3.6 (0-88) months overall for UC because most biologics were first approved in the US (Table 2).

\section{Drug Lag in the EU}

Unapproved IBD drugs accounted for $16.7 \%(2 / 12)$ for CD and 15.4\% (2/13) for UC, making absolute drug lag for both $\mathrm{CD}$ and UC the smallest among regions (Table $1)$. The percentage of first approvals was a high $46.2 \%$ (6/13). Median approval lag was nearly 0 for both CD and UC, making this relative drug lag also the shortest in the world (Table 2). All pre-biologics era IBD drugs were first approved in the EU (online suppl. Table), and although few biologics-era drugs were first approved in the EU, they had only a short approval lag. However, some drugs had approval lags despite being developed in joint US/EU clinical trials, as exemplified by a lag of around 350 days after FDA approval of infliximab for CD (online suppl. Table).

\section{Drug Lag in Japan}

The proportion of unapproved IBD drugs was 33.3\% (4/12) for CD and 23.1\% (3/13) for UC. Absolute drug lag was larger than in the US or in the EU but was the smallest among the Asian countries evaluated (Table 1). Although one drug was first approved in Japan, relative drug lag was long compared with other Asian countries, with approval lags of 74.2 (6.2-687.4) months for CD and 


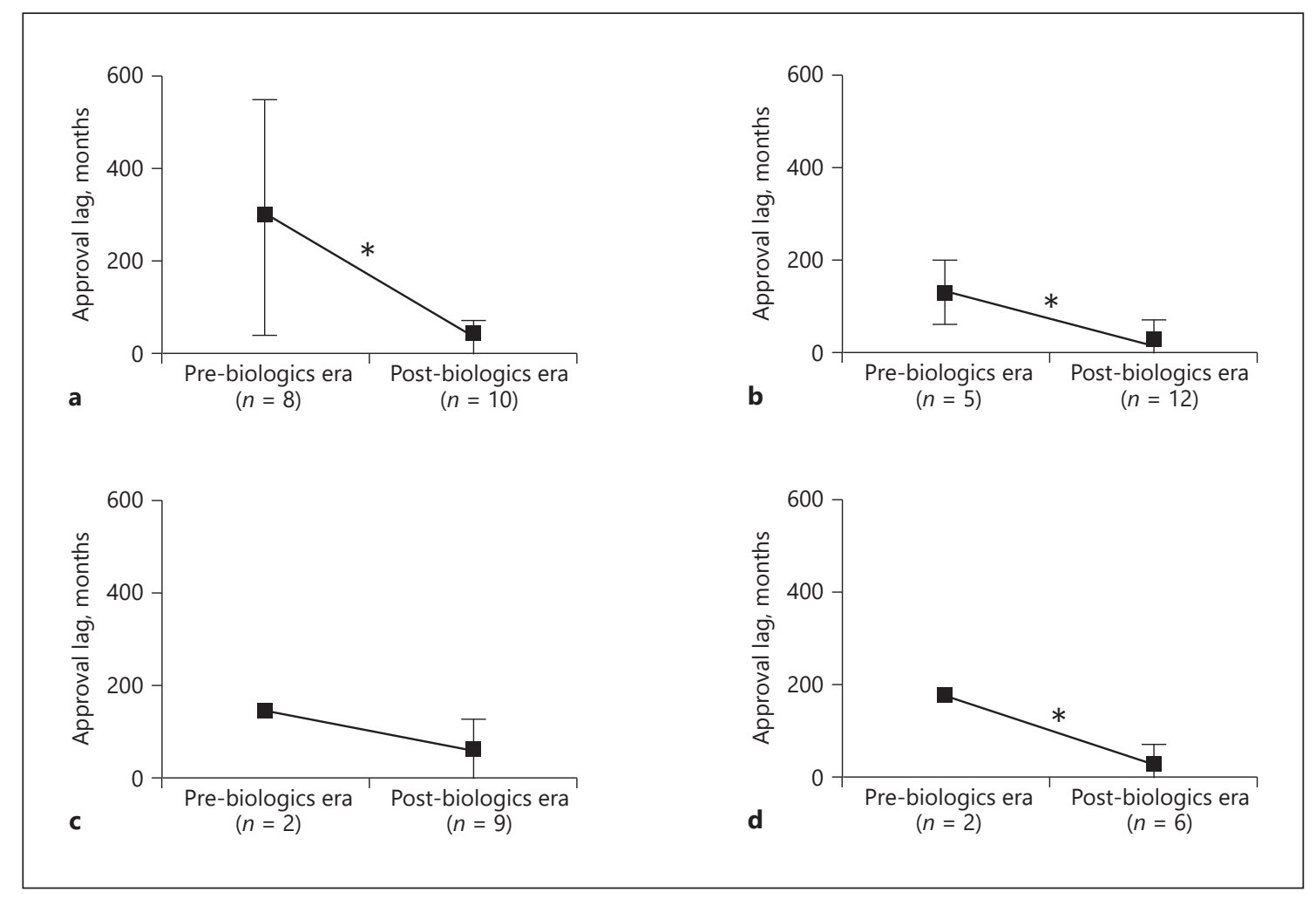

Fig. 1. Comparison of median drug approval lag values between Asian countries before and after the start of the biologics era. Approval lag was significantly shorter for drugs developed in the biologics era in Japan, South Korea, and the Philippines (Mann-Whitney U test). a Japan $(p=0.0005)$. b South Korea $(p=0.0003)$. c Taiwan $(p=0.127)$. d The Philippines $(p=0.0357) .{ }^{*} p<0.05$ ( $p$ value determined by Mann-Whitney $\mathrm{U}$ test).

80.9 (0-687.4) months for UC (Table 2). However, when the scope was limited to only those drugs developed in the biologics era, approval lag was considerably shorter (Fig. 1), and one new drug for IBD, ustekinumab, has been approved in Japan but not in any other Asian countries (online suppl. Table).

\section{Drug Lag in Other Asian Countries}

The overall proportion of unapproved IBD drugs for CD and UD was $41.7 \%(5 / 12)$ and $23.1 \%(3 / 13)$, respectively, in South Korea, 66.6\% (8/12) and 46.2\% (6/13) in Taiwan, and 58.3\% (7/12) and 76.9\% (10/13) in the Philippines (Table 1). Among Asian countries, absolute drug lag was the second smallest in South Korea after Japan. In the relative drug lag analysis for Asia, 2 drugs were first approvals, and both were first approved in South Korea. Relative approval lag for CD and UC was 13.2 (0-133.1) and 16.5 (0-133.1) months, respectively, in South Korea, 42.1 (10.1-207.2) and 53.9 (10.1-147.8) months in Taiwan, and 33.7 (9.9-176.2) and $9.9(0.6-176.2)$ months in the Philippines (Table 2). The median relative approval lag for CD drugs was the shortest in South Korea and the lag for UC drugs was the shortest in the Philippines. As in Japan, approval lag has decreased rapidly in recent years (Fig. 1).

\section{Discussion}

With the rise of IBD as a global disease, drug options for IBD have been increasing since the end of the 20th century, but drug lag between regions remains an issue $[36,37]$. To address this, it is important to assess the state of drug lag and analyze causal factors. To the best of our knowledge, this study is the first to examine drug lag for IBD drugs.

When evaluating drug lag between regions, it is necessary to understand regional differences in the regulatory approval systems. These systems differ between the US, EU, Japan, and other Asian countries. The US, EU, and 
Japan now require applicants to collect data on patient nationality in domestic and global clinical trials for both new drug applications and the addition of indications. This has resulted in the recent trend for conducting global trials in these countries as part of efforts to eliminate drug lag [39]. Although South Korea and Taiwan sometimes ask applicants to conduct small-scale bridging studies with South Korean and Taiwanese patients, respectively, for new drug applications of drugs approved in other countries, Japan is essentially the only Asian country that has been requiring companies to collect clinical trial data from patients on their nationality for both; foreign data alone is acceptable for drug approval in other Asian countries. The period between regulatory approval and insurance approval and the system of insurance approval also varies between countries.

In this study, we found that few IBD drugs are yet to be approved in the West. In contrast, even though Japan had the lowest proportion of unapproved drugs, it still had a large absolute lag compared with the West. However, since the start of the biologics era, absolute drug lag has been decreasing in Japan and other Asian countries not only due to the development of biologics but also due to the recent surge in development of drugs first approved before the biologics era. This may be because delays in initiating drug development, which constitute a major contributor to drug lag, have been reduced due to the elevated clinical importance and expanded drug market resulting from an increased IBD population worldwide $[2,3]$ and the associated increase in the Asian population [3-5].

Almost all IBD drugs were first approved in the US or the EU. Interestingly, all pre-biologics era drugs were first approved in the EU, but most biologics-era drugs have been approved first in the US. A reason for this change may be that it is now common practice for the US and the EU to conduct global clinical trials and submit applications using such data to both regional regulatory authorities at the same time, although the FDA has a shorter review period before approval and has clearly defined priority levels (Fast Track, Accelerated Approval, and Priority Review) for drugs of high clinical importance [40].

Relative approval lag was short in both the US at 3.8 (0-80.5) months for CD and 3.6 (0-88) months for UC, and in the EU, at $0.03(0-13.9)$ and $0(0-13.9)$ months respectively. However, some drugs had an approval lag between the US and the EU despite being developed in joint US/EU clinical trials, such as the lag of around 350 days before approval of infliximab for CD. This illustrates that differences in regional regulatory authorities have a clear impact on drug lag. Among Asian countries, the median relative approval lag was the shortest in South Korea for CD drugs and the shortest in the Philippines for UC drugs, but there was large variation between the drugs and relative drug lag was long compared with that of the West. However, as with absolute drug lag, there has been a clear decrease since the start of the biologics era (Fig. 1). Although Japan had the smallest absolute lag in Asia, relative lag was long at 74.2 (6.2-687.4) months for CD and 80.9 (0-687.4) months for UC. The main reason for this approval lag is that Japan requires companies to collect Japan-specific data even for drugs already approved in other countries, and this can take around 3-7 years per drug [37]. Although the collection of country-specific data aids in the identification of racial differences in responsiveness and in the determination of optimal and safe methods for use [41], it also has the negative effect of delaying the clinical use of effective drugs. In recent years, drugs such as ustekinumab have come out of global clinical trials that also included Japanese patients, eliminating the need to collect country-specific data for approval, and the PMDA in Japan has shortened its review time by enhancing its review system. These developments have resulted in a marked decrease in drug lag. In fact, the newest IBD drug tofacitinib was approved slightly faster by the PMDA than by the FDA or EMA (data not shown). Another reason for the long relative drug lag in Japan seen in this study is that after a delay in initiating development due to the availability of existing drugs, several new 5-ASA drugs have recently been approved, eliminating the absolute drug lag.

Although data on regulatory approval dates in each country or region were collected for this study, delayed insurance approval after regulatory approval was a challenge in some countries. Therefore, the approval date may not always reflect the actual timing of the drug's wide availability for routine clinical use in all patients. One unique aspect of Japan is the well-established national health insurance system, and drugs generally receive insurance approval within 60 days of regulatory approval. Therefore, the period between regulatory approval and clinical availability with insurance coverage for all patients is extremely short.

In this study, we compared drug lag for major IBD drugs between the US, the EU, and Asia and found that although drug lag is decreasing in the West and Asia, there is sometimes lag between the FDA and EMA, as it occurred with infliximab for $\mathrm{CD}$, and therefore, drug lag is not only an Asian problem but a global one. Eliminating drug lag and expanding treatment options would allow patients worldwide to receive the best treatment, re- 
ducing the risks of hospitalization and surgery, and consequently improving quality of life while reducing the financial burden of care $[9,42,43]$. In this age of globalization, elimination of drug lag for the now-global disease of IBD may require efforts toward international adoption of a more standardized approval process due to the timeconsuming nature of moving through different review processes in each country.

\section{Acknowledgments}

We would like to thank Dr. Chang Soo Eun, Dr. Shu Chen Wei, Dr. Jose Sollano, and Dr. Maria Carla Tablante for providing information on regulatory approval dates in each country and Ms. Mika Nakayama and Ms. Junko Kawasaki for their assistance in this study.

\section{Statement of Ethics}

This research was conducted ethically in accordance with the World Medical Association Declaration of Helsinki.

\section{Disclosure Statement}

T.K. received lecture fees from Mitsubishi Tanabe Pharma Co., Ltd., Eisai Co., Ltd., Kyorin Pharmaceutical Co., Ltd., AbbVie Inc., Janssen Pharmaceutical K.K, JIMRO Co., Ltd., Ajinomoto Pharma Co., Ltd., EA Pharma Co., Ltd., Astellas Pharma Inc, Mochida Pharmaceutical Co., Ltd., Asahi Kasei Medical Co., Ltd., Takeda Pharmaceutical Co., Ltd., Gilead Sciences Inc., Celltrion Inc., Nippon Kayaku Co., Ltd., and Alfresa Pharma Co., Ltd.; advisory/consultancy fees from Janssen Pharmaceutical K.K, Pfizer Inc., Kyorin Pharmaceutical Co., Ltd., Mochida Pharmaceutical Co., Ltd., Takeda Pharmaceutical Co., Ltd., Eli Lilly and Company, Ferring Pharmaceutical Co., Ltd., Nippon Kayaku Co., Ltd., Thermo Fisher Scientific Inc., Covidien Japan Inc.; and research grants from EA Pharma Co., Ltd., Thermo Fisher Scientific Inc., and Alfresa Pharma Co., Ltd. T.H. received lecture fees from AbbVie Inc., Kyorin Pharmaceutical Co., Ltd., Eisai Co., Ltd., Mitsubishi Tanabe Pharma Co., Ltd., EA Pharma Co., Ltd., JIMRO Co., Ltd., and ZERIA Pharmaceutical Co., Ltd.

\section{Funding Sources}

No funding was received for this work from any of the above organizations.

\section{References}

1 Baumgart DC, Carding SR: Inflammatory bowel disease: cause and immunobiology. Lancet 2007;369:1627-1640.

2 Vegh Z, Kurti Z, Lakatos PL: Epidemiology of inflammatory bowel diseases from west to east. J Dig Dis 2017;18:92-98.

3 Ng SC, Shi HY, Hamidi N, Underwood FE, Tang W, Benchimol EI, Panaccione R, Ghosh S, Wu JCY, Chan FKL, Sung JJY, Kaplan GG: Worldwide incidence and prevalence of inflammatory bowel disease in the 21st century: a systematic review of population-based studies. Lancet 2018;390:2769-2778.

4 Ng SC, Tang W, Ching JY, Wong M, Chow CM, Hui AJ, Wong TC, Leung VK, Tsang SW, Yu HH, Li MF, Ng KK, Kamm MA, Studd C, Bell S, Leong R, de Silva HJ, Kasturiratne A, Mufeena MNF, Ling KL, Ooi CJ, Tan PS, Ong D, Goh KL, Hilmi I, Pisespongsa P, Manatsathit S, Rerknimitr R, Aniwan S, Wang YF, Ouyang Q, Zeng Z, Zhu Z, Chen MH, Hu PJ, Wu K, Wang X, Simadibrata M, Abdullah M, Wu JC, Sung JJY, Chan FKL; Asia-Pacific Crohn's and Colitis Epidemiologic Study (ACCESS) Study Group: Incidence and phenotype of inflammatory bowel disease based on results from the Asia-pacific Crohn's and colitis epidemiology study. Gastroenterology 2013;145:158-165.e2.
5 Ng WK, Wong SH, Ng SC: Changing epidemiological trends of inflammatory bowel disease in Asia. Intest Res 2016;14:111-119.

6 Cosnes J, Gower-Rousseau C, Seksik P, Cortot A: Epidemiology and natural history of inflammatory bowel diseases. Gastroenterology 2011;140:1785-1794.

7 Lonnfors S, Vermeire S, Greco M, Hommes D, Bell C, Avedano L: IBD and health-related quality of life - discovering the true impact. J Crohns Colitis 2014;8:1281-1286.

8 Kappelman MD, Rifas-Shiman SL, Porter CQ, Ollendorf DA, Sandler RS, Galanko JA, Finkelstein JA: Direct health care costs of Crohn's disease and ulcerative colitis in US children and adults. Gastroenterology 2008;135:1907-1913.

9 Stone CD: The economic burden of inflammatory bowel disease: clear problem, unclear solution. Dig Dis Sci 2012;57:3042-3044.

10 Park KT, Colletti RB, Rubin DT, Sharma BK, Thompson A, Krueger A: Health insurance paid costs and drivers of costs for patients with Crohn's disease in the United States. Am J Gastroenterol 2016;111:15-23.

11 Matsuoka K, Kobayashi T, Ueno F, Matsui T, Hirai F, Inoue N, Kato J, Kobayashi K, Kobayashi K, Koganei K, Kunisaki R, Motoya S, Nagahori M, Nakase H, Omata F, Saruta M, Watanabe T, Tanaka T, Kanai T, Noguchi Y,
Takahashi KI, Watanabe K, Hibi T, Suzuki Y, Watanabe M, Sugano K, Shimosegawa T: Evidence-based clinical practice guidelines for inflammatory bowel disease. J Gastroenterol 2018;53:305-353.

12 Harbord M, Eliakim R, Bettenworth D, Karmiris K, Katsanos K, Kopylov U, Kucharzik T, Molnár T, Raine T, Sebastian S, de Sousa HT, Dignass A, Carbonnel F; ECCO: Corrigendum: Third European Evidence-based Consensus on Diagnosis and Management of Ulcerative Colitis. Part 2: current management. J Crohns Colitis 2017;11:1512.

13 Gomollon F, Dignass A, Annese V, Tilg H, Van Assche G, Lindsay JO, Peyrin-Biroulet L, Cullen GJ, Daperno M, Kucharzik T, Rieder F, Almer S, Armuzzi A, Harbord M, Langhorst J, Sans M, Chowers Y, Fiorino G, Juillerat P, Mantzaris GJ, Rizzello F, Vavricka S, Gionchetti P; ECCO: 3rd European Evidencebased Consensus on the Diagnosis and Management of Crohn's Disease 2016: Part 1: diagnosis and medical management. J Crohns Colitis 2017;11:3-25.

14 Lichtiger S, Present DH, Kornbluth A, Gelernt I, Bauer J, Galler G, Michelassi F, Hanauer S: Cyclosporine in severe ulcerative colitis refractory to steroid therapy. N Engl J Med 1994;330:1841-1845. 
15 Ogata $H$, Matsui T, Nakamura M, Iida $M$, Takazoe M, Suzuki Y, Hibi T: A randomised dose finding study of oral tacrolimus (FK506) therapy in refractory ulcerative colitis. Gut 2006;55:1255-1262.

16 Hanauer SB, Feagan BG, Lichtenstein GR, Mayer LF, Schreiber S, Colombel JF, Rachmilewitz D, Wolf DC, Olson A, Bao W, Rutgeerts P; ACCENT I Study Group: Maintenance infliximab for Crohn's disease: the ACCENT I randomised trial. Lancet 2002;359: 1541-1549.

17 Sands BE, Anderson FH, Bernstein CN, Chey WY, Feagan BG, Fedorak RN, Kamm MA, Korzenik JR, Lashner BA, Onken JE, Rachmilewitz D, Rutgeerts P, Wild G, Wolf DC, Marsters PA, Travers SB, Blank MA, van Deventer SJ: Infliximab maintenance therapy for fistulizing Crohn's disease. N Engl J Med 2004;350:876-885.

18 Rutgeerts P, Sandborn WJ, Feagan BG, Reinisch W, Olson A, Johanns J, Travers S, Rachmilewitz D, Hanauer SB, Lichtenstein GR, de Villiers WJ, Present D, Sands BE, Colombel JF: Infliximab for induction and maintenance therapy for ulcerative colitis. N Engl J Med 2005;353:2462-2476.

19 Hanauer SB, Sandborn WJ, Rutgeerts P, Fedorak RN, Lukas M, MacIntosh D, Panaccione R, Wolf D, Pollack P: Human anti-tumor necrosis factor monoclonal antibody (adalimumab) in Crohn's disease: the CLASSIC-I trial. Gastroenterology 2006;130:323333; quiz 591.

20 Sandborn WJ, Hanauer SB, Rutgeerts P, Fedorak RN, Lukas M, MacIntosh DG, Panaccione R, Wolf D, Kent JD, Bittle B, Li J, Pollack PF: Adalimumab for maintenance treatment of Crohn's disease: results of the CLASSIC II trial. Gut 2007;56:1232-1239.

21 Colombel JF, Sandborn WJ, Rutgeerts P, Enns R, Hanauer SB, Panaccione R, Schreiber S, Byczkowski D, Li J, Kent JD, Pollack PF: Adalimumab for maintenance of clinical response and remission in patients with Crohn's disease: the CHARM trial. Gastroenterology 2007;132:52-65.

22 Reinisch W, Sandborn WJ, Hommes DW, D’Haens G, Hanauer S, Schreiber S, Panaccione R, Fedorak RN, Tighe MB, Huang B, Kampman W, Lazar A, Thakkar R: Adalimumab for induction of clinical remission in moderately to severely active ulcerative colitis: results of a randomised controlled trial. Gut 2011;60:780-787.
23 Sandborn WJ, van Assche G, Reinisch W, Colombel JF, D’Haens G, Wolf DC, Kron M, Tighe MB, Lazar A, Thakkar RB: Adalimum$\mathrm{ab}$ induces and maintains clinical remission in patients with moderate-to-severe ulcerative colitis. Gastroenterology 2012;142:257265.e1-e3.

24 Sandborn WJ, Feagan BG, Stoinov S, Honiball PJ, Rutgeerts P, Mason D, Bloomfield R; Schreiber S; PRECISE 1 Study Investigators: certolizumab pegol for the treatment of Crohn's disease. N Engl J Med 2007;357:228238.

25 Hanauer SB, Kirsner JB: Treat the patient or treat the disease? Dig Dis 2012;30:400-403.

26 Targan SR, Feagan BG, Fedorak RN, Lashner BA, Panaccione R, Present DH, Spehlmann ME, Rutgeerts PJ, Tulassay Z, Volfova M, Wolf DC, Hernandez C, Bornstein J, Sandborn WJ; International Efficacy of Natalizumab in Crohn's Disease Response and Remission (ENCORE) Trial Group: Natalizumab for the treatment of active Crohn's disease: results of the ENCORE Trial. Gastroenterology 2007;132:1672-1683.

27 Sandborn WJ, Feagan BG, Rutgeerts P, Hanauer S, Colombel JF, Sands BE, Lukas M, Fedorak RN, Lee S, Bressler B, Fox I, Rosario M, Sankoh S, Xu J, Stephens K, Milch C, Parikh A; GEMINI 2 Study Group: Vedolizumab as induction and maintenance therapy for Crohn's disease. N Engl J Med 2013;369: 711-721.

28 Feagan BG, Rutgeerts P, Sands BE, Hanauer S, Colombel JF, Sandborn WJ, Van Assche G, Axler J, Kim HJ, Danese S, Fox I, Milch C, Sankoh S, Wyant T, Xu J, Parikh A; GEMINI 1 Study Group: Vedolizumab as induction and maintenance therapy for ulcerative colitis. N Engl J Med 2013;369:699-710.

29 Feagan BG, Sandborn WJ, Gasink C, Jacobstein D, Lang Y, Friedman JR, Blank MA, Johanns J, Gao LL, Miao Y, Adedokun OJ, Sands BE, Hanauer SB, Vermeire S, Targan S, Ghosh S, de Villiers WJ, Colombel JF, Tulassay Z: Ustekinumab as induction and maintenance therapy for Crohn's disease. N Engl J Med 2016;375:1946-1960.

30 Lee HS, Park SK, Park DI: Novel treatments for inflammatory bowel disease. Korean J Intern Med 2018;33:20-27.

31 Wardell WM: Introduction of new therapeutic drugs in the United States and Great Britain: an international comparison. Clin Pharmacol Ther 1973;14:773-790.

32 Wardell WM: The drug lag revisited: comparison by therapeutic area of patterns of drugs marketed in the United States and Great Britain from 1972 through 1976. Clin Pharmacol Ther 1978;24:499-524.
33 Kaitin KI, Mattison N, Northington FK, Lasagna L: The drug lag: an update of new drug introductions in the United States and in the United Kingdom, 1977 through 1987. Clin Pharmacol Ther 1989;46:121-138.

34 Andersson F: The drug lag issue: the debate seen from an international perspective. Int Health Serv 1992;22:53-72.

35 Tsuji K, Tsutani K: Approval of new biopharmaceuticals 1999-2006:comparison of the US, EU and Japan situations. Eur J Pharm Biopharm 2008;68:496-502.

36 Tsuji K, Tsutani K: Approval of new drugs 1999-2007: comparison of the US, the EU and Japan situations. J Clin Pharm Ther 2010;35: 289-301.

37 Wileman H, Mishra A: Drug lag and key regulatory barriers in the emerging markets. Perspect Clin Res 2010;1:51-56.

38 Maeda H, Kurokawa T: Recent trends for drug lag in clinical development of oncology drugs in Japan: does the oncology drug lag still exist in Japan? Int J Clin Oncol 2015;20: 1072-1080.

39 Ueno T, Asahina Y, Tanaka A, Yamada H, Nakamura M, Uyama Y: Significant differences in drug lag in clinical development among various strategies used for regulatory submissions in Japan. Clin Pharmacol Ther 2014;95:533-541.

40 Van Norman GA: Drugs, devices, and the FDA: Part 1: an overview of approval processes for drugs. JACC Basic Transl Sci 2016;1: 170-179.

41 Ramamoorthy A, Pacanowski MA, Bull J, Zhang L: Racial/ethnic differences in drug disposition and response: review of recently approved drugs. Clin Pharmacol Ther 2015; 97:263-273.

42 Lichtenstein GR, Yan S, Bala M, Blank M, Sands BE: Infliximab maintenance treatment reduces hospitalizations, surgeries, and procedures in fistulizing Crohn's disease. Gastroenterology 2005;128:862-869.

43 Feagan BG, Panaccione R, Sandborn WJ, D'Haens GR, Schreiber S, Rutgeerts PJ, Loftus EV Jr, Lomax KG, Yu AP, Wu EQ, Chao J, Mulani P: Effects of adalimumab therapy on incidence of hospitalization and surgery in Crohn's disease: results from the CHARM study. Gastroenterology 2008; 135: 14931499 . 